\title{
HUBUNGAN INTENSITAS KOMUNIKASI ORANG TUA DAN ANAK TERHADAP HASIL BELAJ AR SISWA
}

\author{
Enni Uli Sinaga ${ }^{1, a)}$, Metty Muhariati ${ }^{1, b)}$, Kenty ${ }^{1, c)}$ \\ a)enniulisinaga@yahoo.co.id, b) mettymuhariati@yahoo.co.id, ${ }^{c}$ kenty.unj@gmail.com \\ 1)P rogram Studi Pendidikan Kesejahteraan Keluarga \\ Fakultas Teknik, Universitas Negeri J akarta \\ J In. Rawamangun Muka, J akarta Timur. 13220
}

\begin{abstract}
Abstrak
Masalah komunikasi yang dialami orang tua dengan anak, anak dengan orang tua, guru dengan orang tua akan mengakibatkan anak merasa kesepian. Ketika orang tua tidak memberikan waktu untuk berkomunikasi dengan anak, sehingga anak tidak mau menceritakan pengalaman penting yang didapat saat disekolah, serta anak tidak mau terbuka dan mempercayakan masalah yang sedang dihadapinya kepada orang tua. Tujuan penelitian ini adalah untuk mengetahui dan menganalisis hubungan intensitas komunikasi orangtua dan anak dengan hasil belajar siswa kelas VIII di SMP Bhakti Mulia Jakarta Timur. Penelitian ini adalah penelitian kuantitatif dengan metode survey dan pendekatan korelasi bivariat. Populasi penelitian ini adalah seluruh siswa kelas VIII SMP Bhakti Mulia Jakarta Timur dengan jumlah sampel penelitian sebanyak 82 responden. Data pengujian hipotesis menggunakan analisis parametrik yaitu uji Pearson Product Moment. Hasil perhitungan koefisien korelasi

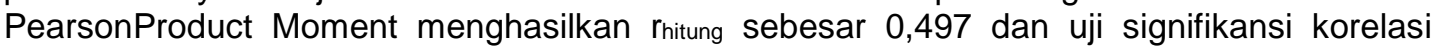
menghasilkan thitung sebesar 5,13 lebih besar dari tabel sebesar 1,99 ( $\alpha=0,05$; $d k=222)$. Hal ini menjelaskan bahwa terdapat hubungan yang positif dan signifikan antara intensitas komunikasi orangtua dan anak dengan hasil belajar siswa. Hasil uji koefisien determinasi sebesar $24,75 \%$ yang menjelaskan besarnya intensitas komunikasi orang tua dan anak terhadap hasil belajar siswa dan sisanya $75,25 \%$ dipengaruhi oleh faktor lain yang tidak diteliti.
\end{abstract}

Kata Kunci : Intensitas komunikasi, orang tua, anak, hasil belajar

\section{The Correlation Between communication intensity of parent and child on learning outcomes of student.}

\begin{abstract}
Communication problems experienced by parents with children, children with parents, teachers with parents will cause the child to feel lonely. When parents didn't have time to communication with the child, they are didn't want to tell important experience acquired in school with parents, and the child didn't want to open and entrust their problem to parents. The purpose of this research was to determine and analyze the correlation of communication intensity for parents and children on learning outcomes of eighth grade students at S MP Bhakti Mulia East J akarta. This research is a quantitative research with survey method and bivariate correlation approach. This research population is all eighth grade students of SMP Bhakti Mulia J akarta Timur with a number of samples are 82 respondents. The hypothesis testing data is using paramentric analysisspecifically Pearson Product Moment test. The correlation coefficient calculation result of Pearson Product Moment produce $r_{\text {count }}$ of 0,497 and significance correlation test produce $t_{\text {count }}$ of 5,13 greater than table of $1,99(a=0,5 ; d k=22)$. It is explained that there is a positive and significant correlation between the communication intensity of parents and children on learning outcomes of students. The determination
\end{abstract}


coefficient test result was $24.75 \%$, which explains the magnitude of communication intensity of parents and children on learning outcomes of students and the rest are $75.25 \%$ influenced by other factors which were not examined.

Keywords: Communication Intensity, Parents, Children, Learning Outcomes

\section{PENDAHULUAN}

Setiap manusia mulai dari lahir sampai akhir hayatnya tidak akan pernah lepas dari sebuah pendidikan. Pendidikan manusia diawali dari pendidikan yang dilakukan ditingkat yang paling kecil, yaitu di dalam sebuah keluarga. Keluarga terdiri dari dari orang tuaa dan anak. Sedari dini, orang tua menanamkan hal-hal positif kepada anaknya dengan memberi tahu bagaimana hal yang benar dan hal yang salah serta melarang anaknya untuk melakukan hal-hal yang buruk.

Kegiatan dalam proses belajar mengajar, guru memiliki peran yang sangat penting dalam membentuk suasana belajar yang kondusif untuk mencapai hasil pembelajaran yang optimal, sehingga tujuan pendidikan dapat tercapai. Target yang hendak dicapai melalui pendidikan adalah menyiapkan generasi yang unggul dan mampu menghadapi segala persoalan yang dihadapinya serta memiliki mental yang kuat dan rasa percaya diri serta memiliki tugas mengembangkan kreativitas dengan tujuan dapat membentuk sumberdaya manusia yang kreatif dan berkualitas. Namun, dalam praktiknya, guru belum mampu menciptakan suasana belajar yang menyenangkan, karena masih banyak guru yang hanya melakukan pembelajaran satu arah, yaitu guru satu-satunya sumber belajar.

Menurut E ducation For All G lobal Monitoring Report 2012 yang dikeluarkan oleh UNE S CO setiap tahunnya, pendidikan di Indonesia berada di peringkat ke-64 untuk pendidikan diseluruh dunia dari 120 Negara. Data Education Develoment Index (EDI) Indonesia, pada 2011 Indonesia berada di peringkat ke-69 dari 127 Negara. Kedua hasil survey tersebut menunjukkan fakta bahwa betapa rendahnya prestasi pendidikan di Indonesia. Hal ini menimbulkan kekhawatiran karena memiliki peran yang berpengaruh terhadap masa depan anak, karena hanya anak yang berprestasi memiliki peluang lebih besar untuk memasuki jenjang pendidikan yang berkualitas.

Keluarga adalah unit terkecil dalam masyarakat yang terdiri dari suami, istri, atau suami istri dan anaknya atau ayah dan anaknya atau ibu dan anaknya. Keluarga merupakan awal proses sosialisasi bagi anak, tempat memperoleh sarana dan prasarana serta cinta kasih dalam bentuk perhatian dari orang tua.

Komunikasi dalam keluarga merupakan salah satu yang mempengaruhi keadaan kehidupan setiap anggota keluarga, karena pendidikan yang dilakukan di lingkungan keluarga oleh orang tua kepada anaknya direfleksikan melalui kegiatan komunikasi yang berlangsung secara tatap muka antara orang tua dan anak. Sedari dini, orang tua menanamkan hal-hal positif kepada anaknya dengan memberi tahu bagaimana hal yang benar dan hal yang salah serta melarang anaknya untuk melakukan hal-hal yang buruk dan negatif. Komunikasi antar orang tua dan anak akan dapat mengenai sikap belajar yang baik, disiplin belajar dan prestasi belajar anak sehingga menjadi motivasi yang baik bagi anak.

Orang tua akan tersenyum puas dan memuji anaknya ketika hasil pencapaian belajar mereka mendapatkan hasil yang baik. Seorang anak merasa lebih dihargai jika orang tuanya menghargai apa yang diperolehnya dan tidak membandingkannya dengan orang lain.

Orang tua harus mengetahui sejauh mana kemampuan anak dan kesulitan yang dihadapi dalam belajar dan mengerjakan tugas. Adanya komunikasi yang baik dengan anak, maka orang tua mengetahui kesulitan- kesulitan apa yang dihadapi anak dalam belajar. 
Kebersamaan yang direfleksikan dengan bertatap muka atau berkomunikasi secara langsung sudah mulai menurun sejalan dengan canggihnya zaman. Dari data survei jurnal internasional mengenai keluarga dan momen kebersamaan, didapatkan empat dari sepuluh orang tua (40 persen) di dunia menyatakan bahwa mereka mendapatkan waktu lebih banyak bersama anak-anaknya dibandingkan beberapa tahun yang lalu, sedangkan tiga dari sepuluh orang tua (30 persen) merasakan total waktu yang dihabiskan bersama dalam porsi yang sama seperti tahun-tahun sebelumnya. Akibatnya dapat menimbulkan kondisi yang memprihatinkan, seperti motivasi dan keinginan belajar anak rendah yang dapat terlihat dari penurunan hasil belajar anak. Perlu diusahakan waktu kebersamaan dalam keluarga dengan menyempatkan diri saling komunikasi tatap muka, antara orang tua dengan anak, dan anak dengan orang tua.

Peneliti melihat, adanya masalah komunikasi yang dialami orang tua dengan anak, anak dengan orang tua, guru dengan orang tua. Peneliti melakukan wawancara dengan Guru BK SMP Bhakti Mulia beliau menjelaskan adanya penurunan hasil belajar siswa. Banyaknya orang tua kurang memberikan waktu untuk berkomunikasi dengan anaknya karena kesibukan bekerja diluar rumah. Kesibukan orang tua menjadi hambatan untuk terlibatnya dalam proses belajar anak didalam keluarga.

Data yang didapat peneliti dari guru BK di SMP Bhakti Mulia pebruari 2016, orang tua kelas VIII sekitar 70\% merupakan keluarga yang memiliki ekonomi menengah kebawah (buru lepas), $30 \%$ keluarga ekonomi mampu yang memiliki pekerjaan tetap (PNS, pengusaha), $90 \%$ merupakan ayah bekerja di luar rumah, $50 \%$ merupakan ibu bekerja diluar rumah, orang tua yang terlibat dalam kemajuan proses belajar anak sangat sedikit dikarenakan kesibukan orang tua bekerja untuk mencari uang sehingga $80 \%$ siswa di kelas VIII SMP Bhakti Mulia mengalami penurunan hasil belajar, terlebih dibidang pelajaran Matematika, Bahasa inggris, dan IImu pengetahuan alam, karena ketiga bidang pelajaran menuntut perhatian dari orang tua supaya anak dapat kegiatan pembelajaran selama di dalam kelas, serta sampai dimana kemampuan anak mengikuti proses belajar mengajar dan kesulitan apa yang dihadapi anak selama proses belajar di sekolah. Komunikasi bertatap muka antara orang tua dengan anak sangat penting dalam meningkatan hasil belajar anak di sekolah .

Kurangnya intensitas komunikasi orang tua dan anak karena orang tua terlalu sibuk bekerja diluar rumah, akibatnya anak merasa kesepian. Ketika orang tua tidak memberikan waktu untuk berkomunikasi dengan anak, sehingga anak tidak mau menceritakan pengalaman penting yang didapat saat disekolah, serta anak tidak mau terbuka dan mempercayakan masalah yang sedang dihadapinya kepada orang tua.

\section{METODE PENELTIIAN}

Penelitian dilakukan di SMP Bhakti Mulia Pulo Gebang. Penelitian ini adalah penelitian kuantitatif dengan metode survey dan pendekatan korelasi bivariat. Populasi penelitian ini adalah seluruh siswa kelas VIII SMP Bhakti Mulia Jakarta Timur dengan jumlah sampel penelitian sebanyak 82 responden. Data pengujian hipotesis menggunakan analisis parametrik yaitu uji Pearson Product Moment.

\section{HASIL DAN PEMBAHASAN}

Hasil belajar dapat diartikan sebagai tingkat keberhasilan siswa dalam mempelajari materi pelajaran di sekolah yang dinyatakan dalam skor yang diperoleh dari hasil tes mengenal sejumlah materi pelajaran tertentu (Susanto, 2013). Anak yang berhasil dalam belajar adalah anak yang berhasil mencapai tujuan-tujuan pembelajaran atau tujuan intruksional setelah ia menerima pengalaman belajarnya di sekolah (Sudjana, 2005:22). Faktor yang mempengaruhi belajar ada dua yaitu faktor internal dan eksternal. Faktor internal adalah faktor yang timbul dari dalam diri anak sendiri. Faktor internal ini meliputi dua aspek yaitu aspek fisiologis (yang bersifat jasmaniah) dan 
aspek psikologis (yang bersifat rohaniah). Faktor eksternal yang mempengaruhi prestasi belajar siswa dikelompokkan menjadi 3 faktor yaitu: faktor keluarga, faktor sekolah, dan faktor masyarakat (Ahmadi, 1997:87).

Komunikasi dalam keluarga sangat penting untuk mendorong anak agar giat dalam belajar. Adanya kasih sayang dan perhatian dari orang tua besar pengaruhnya dalam perkembangan seorang anak, semangat dan motivasi belajar anak akan tumbuh subur karenanya. Komunikasi orang tua dan anak yang saling terbuka, dan jujur membuat anak dapat menuangkan isi hatinya melalui percakapan dengan orang tua sehingga persoalan atau kesulitan anak menjadi berkurang begitu sebaliknya orang tua tua pun mengetahui permasalahan yang sedang dihadapi oleh anak. Jika orang tua terampil dalam berkomunikasi dengan anaknya maka dapat memberikan pengaruh pada perkembangan kepribadian seorang anak.

Djamarah (2004:174) mengatakan, intensitas komunikasi keluarga dapat diartikan sebagai penyampaian pesan yang mendalam dari individu sebagai anggota keluarga kepada yang lain. Untuk menciptakan intensitas komunikasi yang mendalam, orang tua dapat memperhatikan aspek-aspek intensitas komunikasi seperti keterbukaan, pengertian, kejujuran, kepercayaan, dukungan dan tatap muka untuk menciptakan intensita komunikasi yang mendalam antara orang tua dan anak sehingga selalu tercipta hubungan harmonis antara keduanya (Retnaningsih, 2007:174).

Berdasarkan penelitian yang telah dilakukan, pada siswa kelas VIII SMP Bhakti Mulia Jakara Timur diketahui thitung sebesar 5,13 > tabel sebesar 1,99 sehingga dapat disimpulkan bahwa terdapat hubungan positif antara intesitas komunikasi orangtua dan anak dengan hasil belajar siswa kelas VIII SMP Bhakti Mulia. Hubungan intensitas komunikasi orangtua dan anak dengan hasil belajar pun dapat dilihat dari peserta didik bernama no 59 dengan poin 98 mendapat hasil belajar dalam range terendah yaitu sebesar 65 . Sedangkan peserta didik bernama no 40 dengan poin 118 mendapat hasil belajar dalam range tertinggi yaitu sebesar 92 . Dalam penelitian ini, terdapat hubungan positif dan signifikan antara intensitas komunikasi orangtua dan anak dengan hasil belajar dengan jumlah sampel sebanyak 82 responden. Namun tidak semua orang tua melakukan komunikasi yang intens kepada anaknya. Hal tersebut dapat dilihat dari pentingnya intensitas komunikasi orangtua dan anak engan hasil belajar pada siswa kelas VIII SMP Bhakti Mulia Jakarta Timur hanya mencapai $24,75 \%$ sedangkan sisanya dipengaruhi faktor-faktor lain.

Hasil penelitian ini mendukung teori-teori penghubung yang telah dikemukakan para ahli, dimana menurut Gunarsa (2003:174) intensitas komunikasi dan anak dalam keluarga adalah penting, karena dapat mempererat hubungan-hubungan keluarga dan dapat memberikan rasa aman pada mereka, situasi demikian juga dapat membantu meningkatkan hasil belajar.

Menurut Slameto (2003:60) keluarga adalah lembaga pendidikan yang pertama dan utama. Keluarga yang sehat besar artinya untuk mendidik dalam ukuran kecil, tetapi bersifat menentukan mutu pendidikan dalam ukuran besar yaitu pendidikan bangsa dan negara. Maka orangtua perlu memberikan dorongan dan pengertian dapat mungkin untuk dapat mengatasi kesulitan yang dihadapi anak, karena bagaimana cara orangtua mendidik anak sangat penting agar anak mendapat hasil belajar yang baik.

Didukung oleh hasil jurnal penelitian Iternasional Daniel H (2), 2011 yang berjudul "Komunikasi Orang Tua dan Anak dengan Prestasi Akademik Tingkat Negara (Parent-child communication and academic performance. Associations at the within- and between-country level) " hasil penelitian menunjukkan komunikasi orangtua dan anak serta dalam berdiskusi, menentukan keberhasilan akademis, dan peran orang tua merupakan kekuatan yang lebih efektif mempengaruhi prestasi akademik siswa setiap kali orang tua memiliki waktu untuk saling berkomunikasi dengan anak. (Desimone, dkk ; 2009).

Didukung oleh hasil jurnal penelitian Nermeen E. El Nokali (4), 2010 yang berjudul "Keterlibatan orang tua-anak dan Pembangunan Sosial dan Akademik Anak" (Parent Involvement and Children's Academic and Social Development in Elementary School) " menunjukkan bahwa komunikasi antara orangtua dan anak dapat mempengaruhi prestasi akademik, serta eterlibatan 
orang tua juga sangat mendukung dan mendorong untuk meningkatkan prestasi belajar anak yang lebih tinggi.

\section{KELEMAHAN PENELITIAN}

Meskipun penelitian yang dilakukan ini telah berhasil menguji hipotesis yang diajukan, namun peneliti sangat menyadari bahwa penelitian ini tidak sepenuhnya sampai pada tingkat kebenaran yang mutlak, sehingga tidak menutup kemungkinan diadakannya penelitian lanjutan. Penelitian ini masih banyak kekurangan dan kelemahan yang peneliti rasakan di dalam melakukan penelitian ini , antara lain :

1. Keterbatasan responden dikarenakan penelitian ini hanya meneliti siswa/i kelas VIII SMP Bhakti Mulia Jakarta Timur dengan jangka waktu yang kurang maksimal sehingga hasil penelitian ini masih kurang sempurna.

2. Dalam proses pengumpulan data, peneliti tidak bertemu langsung dengan orangtua murid.

3. Keterbatasan sampel, karena dalam penelitian ini sampel yang diambil hanya sebagian kecil responden, hanya pada sekolah tempat penelitian saja yaitu SMP Bhakti Mulia Jakarta Timur, Sehingga hasil penelitian ini hanya berlaku pada daerah populasi penelitian saja dan hasil penelitian ini juga tidak dapat digeneralisasikan.

\section{DAFTAR PUSTAKA}

Ahmadi, A. 2008. Psikologi belajar. Rineka Cipta. Jakarta.

Daniel, H. 2011. Parent-child communication and academic performance. Associations at the withinand between-country level. J ournal for educational research online, (2) 3:15-37

DeSimone, Werner, Jon M., Randy L. 2009. Human Resources Development, $5^{\text {th }}$ dition. SouthWestern Cengage Learning, Mason.

Djamarah, S.B. 2004. Pola Komunikasi O rang Tua dan Anak Dalam Keluarga. Rineka Cipta. Jakarta. Djamarah, S.B., Aswan, Z. 2010. Strategi Belajar Mengajar. Rineka Cipta. Jakarta.

Gunarsa. 2003. Psikologi P raktis Anak,Remaja, dan Keluarga. PT. BPK Gunung Mulia. Jakarta.

Nermeen, E.E.N., Heather, J.B., Elizhabeth, V.D. 2010. Parent Involvement and Children's Academic and Social Development in Elementary School. 10.1111/j/1467-8624.2010.01447.x.

Retnaningsih, H. 2007. Hubungan Intensitas Komunikasi Orang Tua dan Motivasi Belajar Anak. J urnal IImiah Penelitian Psikologi, Vol.12. No. 2.

Sudjana. 2005. Metoda Statistik. Tarsito. Bandung.

Slameto. 2003. Belajar dan Faktor-Faktor yang Mempengaruhinya. Rineka Cipta. Jakarta.

Susanto, H. 2013. Mengembangkan Kemampuan Self Regulation Untuk Meningkatkan Keberhasilan Akademik Siswa. J urnal Pendidikan Penabur. Jakarta. 